\title{
ALDRICH'S SYNDROME: FAMILIAL THROMBOCYTOPENIA, ECZEMA AND INFECTION
}

\author{
BY \\ RONALD R. GORDON \\ From the City General Hospital, Sheffield
}

(RECEIVED FOR PUBLICATION JUNE 22, 1959)

In 1954 Aldrich, Steinberg and Campbell described a family, originally of Dutch extraction, in which the male infants were liable to die at a young age having shown signs of 'draining ears, eczematoid dermatitis and bloody diarrhoea' from the age of a few weeks. They briefly described the clinical features in one child who was a member of this family and who died. They went on to show quite clearly that if the condition which had killed previous male members of the family was the same (as the family itself maintained) then it must have been genetically determined. Since it affected only male members of the family and only some of them, they concluded that the condition must be due to a sex-linked recessive gene which was passed down through the females to the males (in the same way as haemophilia and pseudo-hypertrophic muscular dystrophy). They showed, too, that in the last three generations 16 out of 40 males had been affected and had died within the first 31 months of life. Further evidence of the genetic basis of the condition in Aldrich's family has been produced more recently by Krivit and Good (1959), who report that the two females who appear to carry the gene at the moment, and are reproducing, have produced eight children between them since Aldrich's paper was published. Two of them are girls and are normal, while six of them are boys, three of whom have been affected by the condition. This is what one would expect if it were due to a sex-linked recessive gene. It seems quite definite therefore that in the family described by Aldrich the condition is genetically determined in this way.

Meanwhile Huntley and Dees (1957) have described other white families in which the same condition appears to have been present, and Wolff and Bertucio (1957) have described it in a Negro family. Huntley and Dees contributed considerably towards determining the clinical picture and they described the main features as being 'eczema associated with thrombocytopenic purpura and purulent otitis media'. They described five cases, all of whom died. In only two of these cases, however, was the genetic nature of the condition at all conclusive. These two cases ( 1 and 2 in their series) were brothers. In their Case 3 no family history was obtainable and in their Case 4 the child was adopted and no family history was available. In Case 5 there was a suggestive but unconvincing family history.

Although Wolff and Bertucio reported their Negro family in 1957, it was only briefly, and further details do not seem to have been published. It is possible therefore to include their family as one in which the abnormal gene is carried, but it is not possible to include the individual cases of the family in this review since full details are not available.

Very recently Mills and Winkelmann (1959) have reported a further three cases in two families. Again all the children were male and there was a strong family history in all of them. Two of them were cousins. All three have died.

To date, therefore, seven* families have been reported, who seem to carry this abnormal gene, and full details are available of $16 \dagger$ cases, some of whom do not have a positive family history but are clinically identical with those who do. All 16 were males and all are dead.

The object of the present communication is to report two cases in an English family which also seems to carry the abnormal gene. One has died and the other is still alive.

* Aldrich (1); Huntley and Dees (1); Krivit and Good (2); Wolff and Bertucio (1); Mills and Winkelmann (2).

$\dagger$ Aldrich (1); Huntley and Dees (5); Krivit and Good (7); Mills and Winkelmann (3). 


\section{Case Reports}

Case 1. Patrick G. (54/23984/G) was born on September 30, 1949.

First Admission. On November 2, 1950, at the age of 14 months, he was admitted because of infantile eczema dating from the age of 4 months. This had affected mainly the head, arms, legs and neck. It had also been observed from the age of 4 months that he had a bleeding tendency and that unexplained bleeding had occurred from the nose, ears and gums. This was especially noted by the mother since she had had a brother who was said to have suffered from haemophilia and who died of pneumonia at the age of 1 year, in 1933.

The reason for Patrick's first admission was that some areas of the eczema had started to weep, the serous discharge being bloodstained, and that he had in addition many petechiae and ecchymoses.

The eczema responded well to the dermatologists' treatment but the purpura continued to appear and was shown to be related to a thrombocytopenia which (with the exception of one count) persisted until a splenectomy was performed three years later. The eczema, however, tended to improve and Fig. 1 shows only a quiescent eczema of the ankle, since it was taken primarily to show the purpura. He constantly had similar eczema behind the ears and inconstantly on the face.

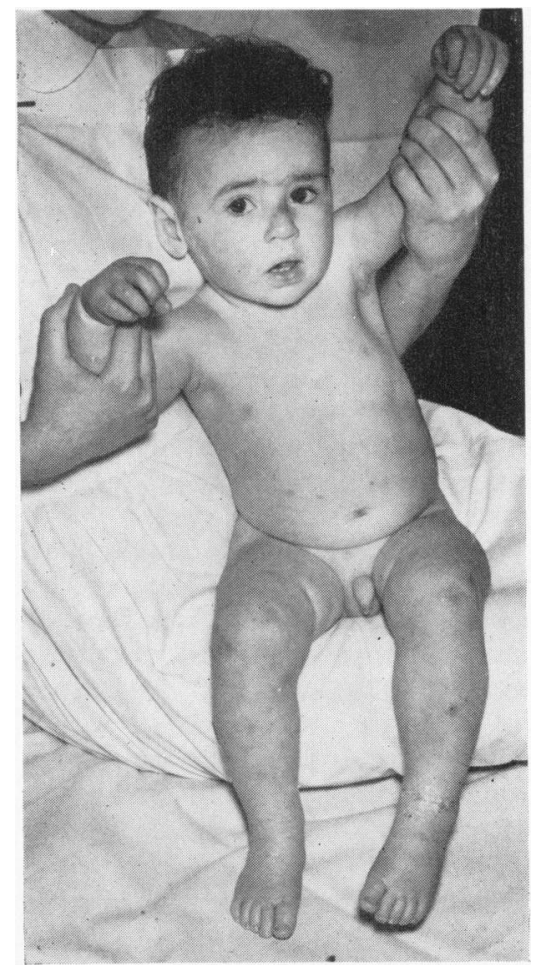

FIG. 1.-Case XVI. Patrick G. Shows severe ecchymoses and flexural eczema at ankles.
The only drug which the child had had before admission was phenobarbitone (for the irritation of his eczema), and withdrawal of this led to no improvement in the purpura.

During the first and subsequent admissions numerous references were made in the notes to the ease with which he picked up infections. He was febrile on many occasions, sometimes without any satisfactory explanation being found; on others he had recurrent otitis media, pyodermia, diarrhoea and respiratory infections.

On December 18, 1950 he was discharged home with a quiescent eczema but with an active purpura and thrombocytopenia. He was somewhat anaemic at this stage ( $\mathrm{Hb} 9 \mathrm{~g} . \%$ ) and was given a course of oral iron. His white cell count was $11,000 / \mathrm{c} . \mathrm{mm}$. and remained normal throughout except for the polymorph response during the acute infections.

Second Admission. He was re-admitted on April 21, aged 19 months, with a recrudescence of his eczema. His platelet count was $178,000 / \mathrm{c} . \mathrm{mm}$. (the only normal count obtained before splenectomy), but this rapidly fell again to a low level and the purpura (which had never really been absent) persisted. At this stage a marrow puncture was performed and was reported as showing 'plenty of platelet-forming megakaryocytes'.

On July 11, 1951 he was discharged for the second time, again with quiescent eczema but still thrombocytopenic.

Third Admission. He was re-admitted on August 22, 1953, aged 3 years 11 months; the eczema was still quiescent but he had discharging ears, impetigo, bleeding gums and profuse purpura. His platelet count was still low. Once again the skin lesions cleared, and on this occasion he was given A.C.T.H. $25 \mathrm{mg}$. b.d. for 10 days (the 'ration' which was available at the time). Since the platelet count showed no response further supplies were not requested.

In view of the fact that this child was known to have had thrombocytopenia of severe degree for over three years without remission (other than for one count), it was felt that splenectomy was indicated and this was performed on December 7, 1953 (Mr. F. J. P. O'Gorman). There was an immediate rise in the platelet count, which at one time went to over $600,000 / \mathrm{c} . \mathrm{mm}$. and then stabilized at a normal level and remained normal till (at least) four days before he died. In association with this there was a complete disappearance of his purpura and bleeding tendency until the final illness. On January 14, 1954, he was discharged for the third time.

Fourth Admission. On January 26, 1954, 12 days after his third discharge, he was admitted as an emergency, having been gravely ill for 24 hours. He was unconscious with a low B.P. (55/0) and no fever. In spite of this the clinical condition seemed to be compatible with a septicaemia and he was treated accordingly. He proceeded to develop a pneumococcal meningitis and responded well to treatment. Once this was stopped he relapsed, and this time the meningitis was said to be 
staphylococcal in origin. This also responded satisfactorily to treatment.

He was discharged home for the fourth time on April 4, 1954 . His platelet count was still normal and it had been established that he did not have agammaglobulinaemia.

Fifth Admission. This was on July 5, 1954 for dental extractions which proceeded without incident.

When seen in the out-patient department on October 1, 1954, he was found to be well and without purpura. His platelet count was $228,000 /$ c.mm.

Sixth Admission. He was admitted as an emergency on October 5, 1954, aged 5 years, having been ill for only 12 hours with symptoms similar to the illness of his fourth admission, but his condition had deteriorated very rapidly and on admission he was moribund. At autopsy he had bilateral adrenal haemorrhage of the kind found in the Waterhouse-Friderichsen syndrome. No proof of a septicaemia was obtained on this occasion.

Summary. This boy showed signs of infantile eczema and purpura from the age of 4 months. A maternal uncle had suffered from a bleeding tendency and had died of pneumonia at the age of 1 year. The present patient's eczema persisted but tended to improve as the years went by; his purpura was associated with thrombocytopenia and they both persisted until splenectomy was performed at the age of 4 years 2 months. Thereafter the platelets rose to a normal level and the bleeding tendency disappeared. He had always tended to show signs of minor infections but some weeks after splenectomy he developed pneumococcal septicaemia with meningitis and then relapsed with a staphylococcal meningitis. He responded well to treatment. At the age of 5 years, 10 months after splenectomy, he still had a normal platelet count, but five days later he was admitted moribund having been ill for only 12 hours (again with symptoms suggestive of septicaemia) and he died shortly afterwards. Autopsy showed massive bilateral adrenal haemorrhage.

Case 2. Christopher G., brother of Patrick, was born on August 31, 1957.

Between the births of these two children (see the family tree in Fig. 2) a boy and a girl had been born, both of whom are perfectly healthy and show none of the manifestations of the condition.

Christopher was also thought to be normal until he was 3 months old when the family doctor (Dr. E. D. Forster) noted that he had petechiae on the neck (Fig. 3). At 4 months he was admitted for investigation and by that time he had some eczema behind the left ear although his eczema never became so severe as Patrick's. On admission he had a definite thrombocytopenia as a cause of his purpura and his ability to pick up infection was

also demonstrated during his stay in hospital since he developed furunculosis, pyuria and frequent bronchitis but never otitis media. It was established that he also did not have agammaglobulinaemia and his white count throughout was normal.

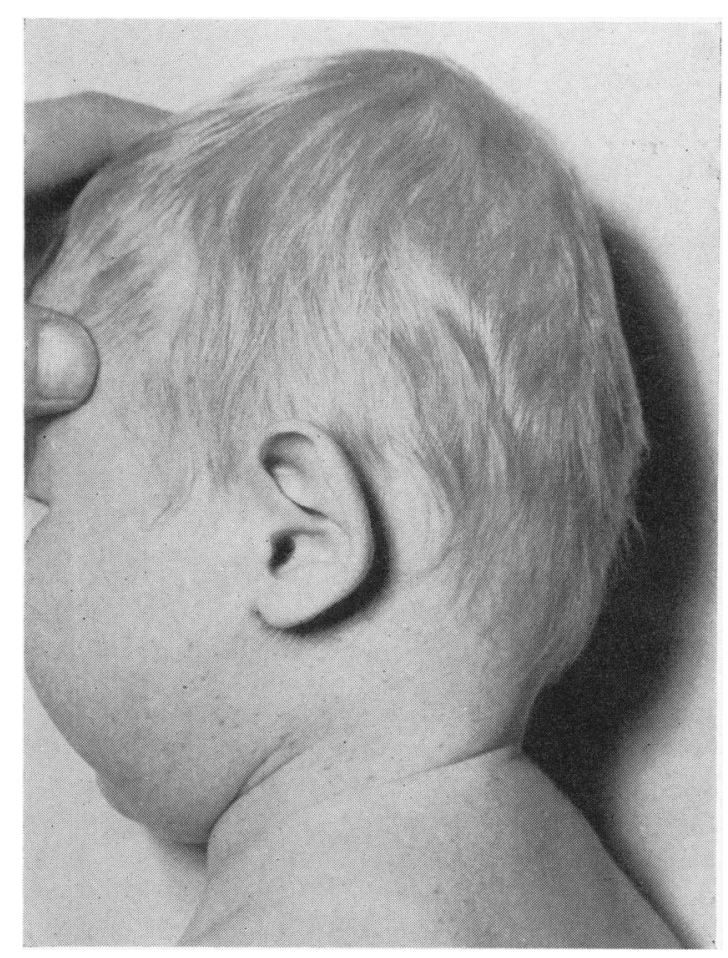

FIG. 3.-Case XVIII. Christopher G. Shows purpura on neck and minimal changes of eczema behind ear. 
Marrow puncture was performed and reported as showing 'adequate megakaryocytes present but reduced platelet formation'.

Attempts to stimulate platelet formation by means of A.C.T.H. and prednisolone were only temporarily successful. In view of our experience with Patrick after splenectomy it was decided that this operation was not indicated in Christopher's case so he was discharged home, still with a low platelet count.

$\mathrm{He}$ has remained well since, apart from frequent respiratory infections during the winter months, and he is now a well developed toddler who still gets occasional crops of petechiae but whose eczema is well healed.

Summary. Christopher G., brother of Patrick, had petechiae at 3 months and slight eczema at 4 months. He has always been liable to pick up infections. He has thrombocytopenia which only temporarily responds to
A.C.T.H. and steroids. He does not have agammaglobulinaemia. He is now (April, 1960) a healthy child with occasional petechiae and recurrent respiratory infections.

Charts showing the changes in the platelet counts in response to A.C.T.H., prednisolone and splenectomy in the two brothers are shown in Figs. 4 and 5.

Table 1 shows the main features in the 18 cases described so far. All the cases showed eczema but this was of variable severity.

All the cases showed purpura and, except for Case VIII, they all showed persistent thrombocytopenia, too. In Case VIII only one count was done and it was normal, but this may well have been a temporary spontaneous rise such as occurred in

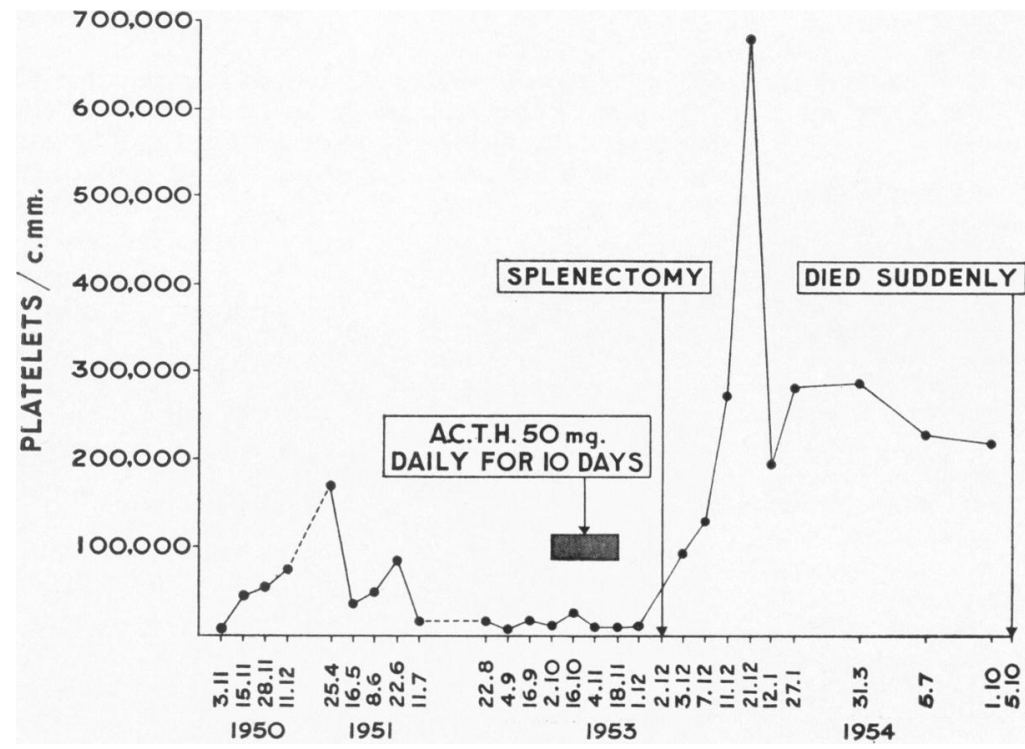

FIG. 4.-Shows platelet level over four years of Patrick G. with absence of response to a small dose of A.C.T.H. and dramatic response to splenectomy which was maintained until at least four days before his sudden death.

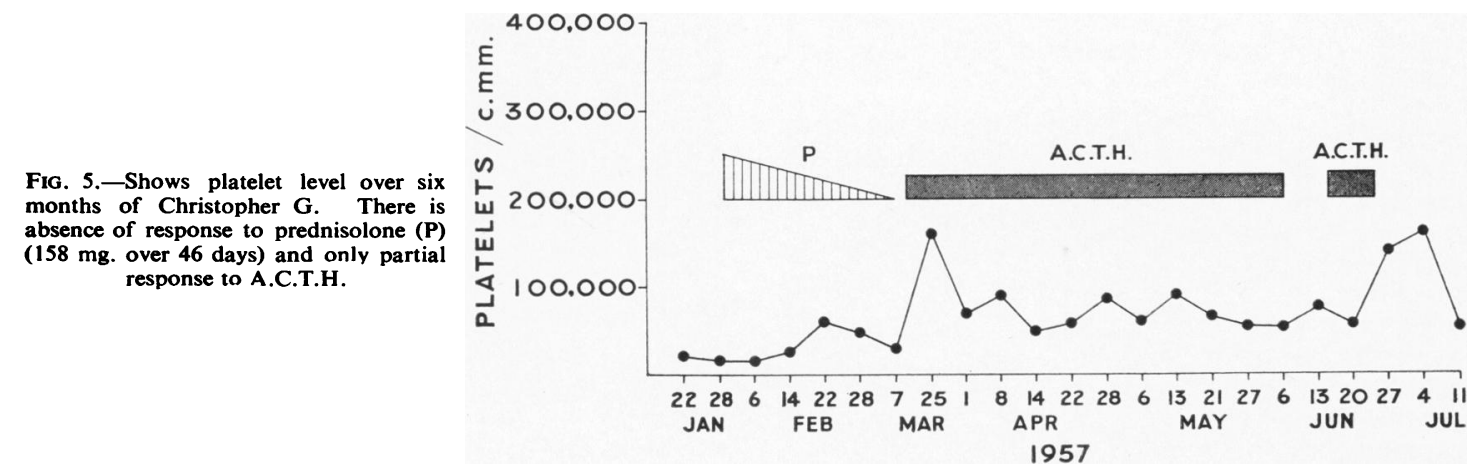


TABLE 1

ANALYSIS OF CASES REPORTED IN THE LITERATURE

\begin{tabular}{|c|c|c|c|c|c|c|c|c|c|c|c|c|c|c|c|c|c|c|c|}
\hline \multirow[b]{3}{*}{$\begin{array}{l}\text { Age at onset } \\
\text { Age at death }\end{array}$} & & \multicolumn{18}{|c|}{ Case Number } \\
\hline & & 1 & II & III & 4 & 5 & 6 & VII & VIII & 9 & $\mathbf{X}$ & 11 & 12 & XIII & XIV & XV & XVI & XVII & XVIII \\
\hline &.. & $11 \mathrm{~m}$. & $\begin{array}{r}3 \mathrm{~m} . \\
22 \mathrm{~m} .\end{array}$ & $\begin{array}{l}5 \mathrm{~d} . \\
2 \mathrm{yr} .\end{array}$ & $\begin{array}{r}2 \mathrm{w} . \\
14 \mathrm{~m} .\end{array}$ & $\begin{array}{l}2 \mathrm{w} . \\
2 \mathrm{yr} .\end{array}$ & $\begin{array}{ll}3 \mathrm{~m} . \\
7 \mathrm{yr} .\end{array}$ & $\begin{array}{l}5 \mathrm{~m} . \\
3 \mathrm{yr} .\end{array}$ & $\begin{array}{l}3 \mathrm{~d} . \\
2 \mathrm{yr} .\end{array}$ & $\begin{array}{l}1 \mathrm{~d} . \\
8 \mathrm{~m} .\end{array}$ & $\begin{array}{l}3 \mathrm{w} . \\
1 \mathrm{yr} .\end{array}$ & $11 \mathrm{~d}$. & $\begin{array}{l}6 \mathrm{~d} . \\
2 \mathrm{yr} .\end{array}$ & $\begin{array}{r}9 \mathrm{~d} . \\
23 \mathrm{~m} .\end{array}$ & $\begin{array}{c}\text { Birth } \\
15 \mathrm{~m} .\end{array}$ & $\begin{array}{l}2 \mathrm{w} . \\
5 \mathrm{~m} .\end{array}$ & $\begin{array}{l}2 \mathrm{w} . \\
3 \mathrm{yr} .\end{array}$ & $\begin{array}{l}4 \mathrm{~m} . \\
5 \mathrm{yr} .\end{array}$ & $3 \mathbf{~ m}$. \\
\hline $\begin{array}{l}\text { Clinical features: } \\
\text { Purpura } \\
\text { Thrombocytopenia } \\
\text { Eczema }\end{array}$ & $\begin{array}{l}\cdots \\
\cdots \\
\cdots\end{array}$ & $\begin{array}{l}+ \\
+ \\
+\end{array}$ & $\begin{array}{l}+ \\
+ \\
+\end{array}$ & $\begin{array}{l}+ \\
+ \\
+\end{array}$ & $\begin{array}{l}+ \\
+ \\
+\end{array}$ & $\begin{array}{l}+ \\
+ \\
+\end{array}$ & $\begin{array}{l}+ \\
+ \\
+\end{array}$ & $\begin{array}{l}+ \\
+ \\
+\end{array}$ & $\begin{array}{l}+ \\
? \\
+\end{array}$ & $\begin{array}{l}+ \\
+ \\
+\end{array}$ & $\begin{array}{l}+ \\
+ \\
+\end{array}$ & $\begin{array}{l}+ \\
+ \\
+\end{array}$ & $\begin{array}{l}+ \\
+ \\
+\end{array}$ & $\begin{array}{l}+ \\
+ \\
+\end{array}$ & $\begin{array}{l}+ \\
+ \\
+\end{array}$ & $\begin{array}{l}+ \\
+ \\
+\end{array}$ & $\begin{array}{l}+ \\
+ \\
+\end{array}$ & $\begin{array}{l}+ \\
+ \\
+\end{array}$ & $\begin{array}{l}+ \\
+ \\
+\end{array}$ \\
\hline $\begin{array}{l}\text { Infections: } \\
\text { Pyodermia } \\
\text { Pneumonia } \\
\text { Otitis media } \\
\text { Meningitis } \\
\text { Septicaemia } \\
\text { Pyrexia . . }\end{array}$ & \begin{tabular}{l|}
$\cdots$ \\
$\cdots$ \\
$\cdots$ \\
$\cdots$ \\
$\cdots$
\end{tabular} & $\begin{array}{l}+ \\
+ \\
+ \\
+\end{array}$ & $\begin{array}{l}+ \\
+ \\
+\end{array}$ & $\begin{array}{l}+ \\
+ \\
+\end{array}$ & $\stackrel{+}{+}$ & $\begin{array}{l}+ \\
+\end{array}$ & $\begin{array}{l}+ \\
+\end{array}$ & $\begin{array}{l}+ \\
+\end{array}$ & $\begin{array}{l}+ \\
+\end{array}$ & $\begin{array}{l}+ \\
+\end{array}$ & + & $\begin{array}{l}+ \\
+ \\
+ \\
+\end{array}$ & $\begin{array}{l}+ \\
+ \\
+\end{array}$ & $\begin{array}{l}+ \\
+\end{array}$ & + & + & $\begin{array}{l}+ \\
+ \\
+ \\
+\end{array}$ & $\begin{array}{l}+ \\
+ \\
+ \\
+ \\
+\end{array}$ & + \\
\hline $\begin{array}{l}\text { Treatment of throm } \\
\text { cytopenia: } \\
\text { A.C.T.H. } \\
\text { Steroids ... } \\
\text { Splenectomy } \\
\text { Mode of death .. }\end{array}$ & $\begin{array}{c}\text { bo- } \\
\ldots \\
\cdots \\
\cdots \\
\cdots\end{array}$ & $\stackrel{+}{\mathbf{H}}$ & + & $\begin{array}{l}+ \\
+ \\
+ \\
\mathbf{I}\end{array}$ & I & $\begin{array}{r}+ \\
+ \\
\mathbf{H}\end{array}$ & $\begin{array}{l}+ \\
+ \\
\mathbf{I}\end{array}$ & $\mathbf{H}$ & $\mathbf{H}$ & I & $\begin{array}{l}+ \\
+ \\
+ \\
\mathbf{H}\end{array}$ & I & $\begin{array}{l}+ \\
I\end{array}$ & $\mathbf{I}$ & $\begin{array}{l}+ \\
\mathbf{I}\end{array}$ & $\begin{array}{l}+ \\
+ \\
\mathbf{I}\end{array}$ & $\begin{array}{l}+ \\
\mathbf{I}\end{array}$ & $\begin{array}{l}+ \\
+ \\
\mathbf{H}\end{array}$ & $\begin{array}{l}+ \\
+ \\
\mathbf{A}\end{array}$ \\
\hline
\end{tabular}

Cases with strong family histories in Roman numerals, those without in Arabic. Case 1 is Aldrich's original case; Case XIII Krivit and Good's follow-up of Aldrich's family; Cases II-6 are those of Huntley and Dees; Cases VII-XIII are those of Krivit and Good; Cases XIV-XVI are those of Mills and Winklemann; Cases XVII and XVIII are described in the present communication. We have not been able to trace details of Wolf and Bertucio's family.

$\mathbf{H}=$ death from haemorrhage; $\mathbf{I}=$ death fom infection; $\mathbf{A}=$ alive.

Patrick. The thrombocytopenia is very important diagnostically since it is the only positive laboratory finding which occurs as an essential part of the syndrome.

Infection of one kind or another occurred in all the cases and was responsible for at least 11 of the deaths which have occurred. It should be noted how frequently otitis media has been present but this is almost certainly a reflection of these children's poor resistance to infection rather than of any specific defect in their middle ears.

Since the family history is so important cases with a strongly suggestive family history have been numbered in Table 1 differently from those without. The two cases recorded in the present communication, apart from being brothers, had an uncle who died in infancy apparently from the same condition. The mother of that child, i.e. the grandmother of our two cases, is alive and has given a detailed account of him. He died of pneumonia at the age of 1 year (1933) but before then she was told by the family doctor that he suffered from 'haemophilia'. This was because he bled very easily and he frequently came out in 'large bruises just like Patrick's'. The rest of the family history (Fig. 2) shows that two other male children died young but there was no evidence to show that they had either a haemorrhagic tendency or eczema.

Unfortunately no further family history is available since the grandmother, Mrs. T., went to New Zealand as a child (her parents having died) and she has completely lost touch with her mother's family. She thinks that her mother had some sisters but does not know where their descendants might be.

\section{Discussion}

Although the various clinical aspects of this condition occur separately, and some of them quite commonly, it is unusual for them all to occur in one individual and certainly in members of the same family. Long before we read the original papers on this subject we had decided that this was an unusual family. There are four main features of the condition and they will be discussed separately. In each case the patient has been a male and the symptoms have appeared within the first six months of life.

Thrombocytopenia. This has led to the most common symptom, namely, bleeding. This includes purpura, epistaxis, 'bloody diarrhoea', haematuria, bleeding gums and cerebral haemorrhage, in fact any of the manifestations of bleeding which occur with thrombocytopenia at any age. Six of the 17 deaths appear to have been due to haemorrhage but in two of these (including Patrick) the haemorrhage was into the adrenals and may have been secondary to a fulminating septicaemia.

The cause of the thrombocytopenia in these cases is no clearer than it usually is in "essential thrombocytopenia'. There are certainly adequate numbers 
of megakaryocytes present in the bone marrow so that either they do not produce enough platelets or the platelets they do produce have a shorter life than normal. The latter could result either from a defect in the platelets themselves or from the presence of a platelet-agglutinating antibody. No evidence of such an antibody was found in two of Krivit and Good's patients and, in any case, if the condition is genetically determined some congenital defect in the production or formation of platelets seems more likely than excessive destruction of normal platelets.

We do not even know yet whether the condition is congenital or not. Since the only part of the syndrome which is likely to be present at birth is the thrombocytopenia, it will be necessary to do platelet counts on the cord blood of future infants born to the affected families. Although Case XIV is shown as having symptoms from birth, this information was based on the mother's history and not on observation.

Eczema. This appears to be identical with the usual infantile eczema except that in certain cases bleeding has occurred into the eczematous areas. The severity of the skin lesions has varied from time to time even in one patient and has varied considerably from one patient to another. Even in our two brothers the eczema was more severe in Patrick than in Christopher. Mills and Winkelmann (1959) point out that the eczema is the least specific of the clinical features in these children and we agree with this.

Liability to Infection. This is the most difficult part of the syndrome to define, since, of course, most infants in the first year of life are liable to pick up infections. The infections which these affected babies have are of the usual variety and include pyodermia and respiratory infections in addition to the otitis media which has occurred in nearly every case. It is characteristic of these children, too, that they run fevers for which no satisfactory explanation can be found. It can be seen from Table 1 that a considerable number die from infections in spite of antibiotic therapy. This has occurred in those on whom splenectomy has not been performed (Cases 4, 9, 11, 12, XIII, XIV, XVI) as well as in those whose spleens have been removed (Cases II, III, 6, XV, ?XVII). It is well known that King and Shumacker (1952) and Smith, Schulman, Stern and Erlandson (1956) have suggested that splenectomy in young children may be followed by death from fulminating infection. In Smith's series this occurred in $28 \%$ of his 50 patients who had had splenec- tomy performed under the age of 2 years for any reason at all, including trauma. In spite of the fact that there is evidence against this contention (Gofstein and Gellis, 1956) as well as in favour of it, we felt that splenectomy should not be undertaken in Christopher. Krivit and Good (1959) are also of the opinion that there is an increased liability to severe infection after splenectomy. They were, however, unable to find any alteration in known immune mechanisms in two of their cases on whom intensive investigations were performed. In all cases on whom gamma globulin estimations have been performed it has been found to be present in normal amounts, and the white cell counts have also been normal. There is therefore no explanation for the liability of these infants to infection.

Family History. There have now been reported eight families showing both the clinical features of Aldrich's syndrome and the family history, which is strongly suggestive of its genetic basis. In the other cases all the affected children have been males but there has been no clear-cut history of the condition occurring in other male relatives. Since it was the genetic basis of the condition which Aldrich laid down, it seems wise to limit the syndrome bearing his name to those cases in which there seems to be a reasonable certainty that, in addition to occurring in males, it has been genetically determined by a sex-linked recessive gene.

It is, of course, often found that conditions such as infantile eczema are familial, and they are often thought to indicate a familial tendency to allergy. Thrombocytopenia, too, is often thought to have an 'allergic' basis and it is not surprising that American writers have concentrated on the possibility of one allergic factor being responsible for both parts of the syndrome. Although in certain cases true allergic responses have been obtained, there does not appear to be any clear-cut evidence that the symptoms are due to any specific antigen-antibody reaction. Following the usual British practice at the present time, skin reactions, etc. were not performed on either of our two patients so that information on this point is not available.

As with all familial conditions, the parents and relatives all worry about what is likely to happen to future children who are born into the family. Once the genetic basis becomes clear, as we believe it has in this syndrome, it becomes easier for the physician to give the family the facts, as far as they are known, and this can reassure the relatives considerably even though they realize that half of the further male children may be affected.

It is customary, whenever someone is writing 
about a relatively new syndrome, to say that cases are likely to be found more frequently in the future once people start looking for them. This is not likely to happen to any great extent in Aldrich's syndrome since, although other families will probably be described, it is unlikely that they are at all numerous. The importance of the syndrome lies more in the fact that it is a newly recognized disease process due to a sex-linked gene, and the components of the syndrome all occur fairly commonly as separate entities.

\section{Summary}

A further family is reported which seems to suffer from Aldrich's syndrome.

The syndrome consists of thrombocytopenic purpura, eczema and infection occurring in male infants and leading eventually to death from haemorrhage or infection. It is genetically determined and is due to a sex-linked recessive gene.

It has not yet been shown whether or not the condition is congenital.
I would like to thank Dr. H. R. Vickers and Dr. I. B. Sneddon for their cooperation in the management of the children, Dr. A. J. N. Warrack for the autopsy findings, Dr. S. Varadi for the reports on the bone marrow and for helpful advice, and Dr. E. D. Forster for his great assistance with the family.

\section{REFERENCES}

Aldrich, R. A., Steinberg, A. G. and Campbell, D. C. (1954), Pedigree demonstrating a sex-linked recessive condition characterised gree draining Pediatrics, 13, 133.

Gofstein, R. and Gellis, S. S. (1956). Splenectomy in infancy and childhood. A.M.A. J. Dis. Child., 91, 566.

Huntley, E. C. and Dees, S. C. (1957). Eczema associated with thrombocytopenic purpura and purulent otitis media. Pediatrics, 19,351 .

King, H. and Shumacker, H. G. (1952). Splenic studies 1. Susceptibility to infection after splenectomy performed in infancy. Ann. Surg., 136, 239.

Krivit, W. and Good, R. A. (1959). Aldrich's syndrome (thrombocytopenia, eczema and infection in infants). A.M.A.J. Dis. Child., 97, 137.

Mills, S. D. and Winkelmann, R. K. (1959). Eczema, thrombocytopenic purpura and recurring infections. A.M.A. Arch. Derm., 79, 466.

Smith, C. H., Schulman, I. Stern, G. and Erlandson, M. (1956) Benefits and hazards of splenectomy in severe chronic anemias in children. Proceedings of the 8th International Congress of in children. Proceedings of the 8th Interna

Wolff, J. A. and Bertucio, M. (1957). A sex-linked genetic syndrome in a Negro family manifested by thrombocytopenia, eczema, bloody diarrhea, recurrent infection, anemia and epistaxis. A.M.A. J. Dis. Child., 93, 74. 